\title{
ANALISIS PROSES PACKAGING DAN STUFFING PERUSAHAAN FURNITUR LOKAL DALAM MENJAGA EKSISTENSI PERSAINGAN GLOBAL (STUDI KASUS: UD SURYA ABADI FURNITURE, SUKOHARJO, JAWA TENGAH)
}

\author{
ANALYSIS OF THE PACKAGING AND STUFFING PROCESS OF LOCAL FURNITURE \\ COMPANIES IN MAINTAINING GLOBAL COMPETITION EXISTENCE \\ (CASE STUDY: UD SURYA ABADI FURNITURE, SUKOHARJO, JAWA TENGAH)
}

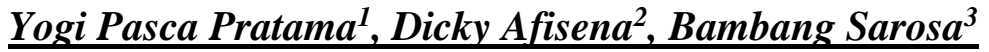

E-mail: yogipasca@gmail.com

Fakultas Ekonomi dan Bisnis, Universitas Sebelas Maret

Jl. Ir. Sutami No.36A, Jebres, Kota Surakarta, Jawa Tengah, Kode Pos 57126, Indonesia

ABSTRACT

Indonesia has great potential in developing the furniture industry sector The abundance of raw materials and high labor numbers should be optimized to encourage the furniture industry in Indonesia in the international furniture trade. However, in reality, the Indonesian furniture industry has increasingly been eliminated in the arena of international furniture trade. Therefore, it is necessary to consider how the furniture industry actvally manages the company. One of the influential factors in furniture exports is how to manage the supply chain or logistics of the furniture industry, where one of them is related to the process of packaging and stuffing of furniture products. As a representation, this study tries to describe how the packaging and stuffing process is carried out by UD Surya Abadi Furniture, pne of the furniture industries located in Sukoharjo Regency, Central Java. This research is a descriptive study, where data is collected by observation, interview, and documentation techniques. The results of this study discuss the packaging procedures, materials used and feasibility tests, and how the procedures and benefits obtained from the stuffing process at UD Surya Abadi Furniture. The conclusion obtained is that the description of the packaging and stuffing process that is carried out is quite good with the use of materials that meet the standards. Nevertheless, the process of packaging and stuffing at UD Surya Abadi Furniture is still done with manual counting so that it is not optimal.

Keywords: furniture industry, packaging, stuffing

Indonesia mempunyai potensi besar dalam mengembangkan sektor industri furnitur. Melimpahnya bahan baku serta angka tenaga kerja yang tinggi seharusnya dapat dioptimalkan untuk mendorong industri furnitur di Indonesia dalam perdagangan 
furnitur internasional. Akan tetapi pada kenyataanya, industri furnitur Indonesia semakin tahun semakin tersingkir dalam kancah perdagangan funitur internasional. Oleh karena itu, perlu diperhatikan bagaimana sebenarnya industri furnitur dalam mengelola perusahaannya. Salah satu yang berpengaruh dalam ekspor furnitur adalah bagaimana mengelola rantai pasok atau logistik industri furnitur, dimana salah satunya berhubungan dengan proses packaging dan stuffing produk furnitur. Sebagai representasi, penelitian ini mencoba mendeskripsikan bagaimana proses packaging dan stuffing yang dilakukan oleh UD Surya Abadi Furniture, salah satu industri furnitur yang terletak di Kabupaten Sukoharjo, Jawa Tengah. Penelitian ini merupakan penelitian deskriptif, di mana pengumpulan data dengan teknik observasi, wawancara, dan dokumentasi. Hasil penelitian ini membahas mengenai prosedur packaging, bahan yang digunakan serta uji kelayakan, serta bagaimana prosedur dan manfaat yang diperoleh dari proses stuffing di UD Surya Abadi Furniture. Kesimpulan yang didapatkan yaitu deskripsi proses packaging dan stuffing yang dijalankan sudah cukup baik dengan penggunaan bahan yang memenuhi standar. Meskipun demikian, proses packaging dan stuffing pada UD Surya Abadi Furniture masih dilakukan dengan penghitungan manual sehingga kurang optimal.

Kata Kunci: industri furnitur, packaging, stuffing

\section{PENDAhUluan}

Sebagai salah satu negara dengan sumber daya alam yang melimpah, Indonesia mempunyai potensi besar dalam mengembangkan sektor industri furnitur. Melimpahnya bahan baku untuk furnitur terutama yang berbahan dasar kayu, rotan maupun bambu, pada kenyataannya belum mampu mernbawa posisi Indonesia dalam kancah perdagangan furnitur global dibandingkan dengan negara-negara lain.

Posisi Indonesia sebagai negara penghasil furnitur di dunia masih sangat minim dengan kontribusi kurang dari 1 persen terhadap pasar global industri furnitur. Pencapaian Indonesia masih relatif rendah jika dibandingkan dengan Brazil, Vietnam dan Polandia yang mencapai 2 persen. Lebih jauh lagi dibandingkàn dengan Tiongkok yang mampu menyumbang 31 persen produksi mebel dunia di tahun 2011.[1]

Hal tersebut cukup disayangkan karena selain sumberdaya alam yang melimpah, ketersediaan tenaga kerja di Indonesia juga tinggi. Hal ini sesuai dengan karakteristik industri furnitur yang memang membutuhkan banyak tenaga kerja karena pada umumnya merupakan industri padat karya.

Terminologi furnitur digunakan untuk mendeskripsikan perabotan rumah tangga yang mempunyai berbagai fungsi, seperti untuk tempat penyimpanan barang, berfungsi sebagai tempat duduk, sebagai tempat tidur, untuk menulis sesuatu atau meletakkan sesuatu di atasnya. Contoh furnitur yang mempunyai fungsi sebagai tempat menyimpan barang pada umumnya dilengkapi dengan pintu, rak dan laci, dalam bentuk seperti lemari buku, lemari pakaian, dan lain sebagainya. Furnitur pada umumnya diproses sehingga menghasilkan produk yang memiliki tekstur dan warna yang indah disebabkan proses akhir yang halus.[2]

Indusrti furnitur mencakup pengolahan bahan baku seperti kayu, rotan, atau bahan baku lainnya. Bahan baku tersebut kemudian diolah untuk meningkatkan nilai tambah dan manfaat yang lebih tinggi menjadi produk barang jadi furnitur. Sehingga industri furnitur dalam pengertian ini merupakan pihak yang mengolah bahan baku sampai menjadi barang furnitur yang siap dikonsumsi oleh konsumen.[3]

Konsentrasi industri furnitur terbanyak ada di daerah Jepara, Klaten, Pasuruan, Sidoarjo, Gresik, Cirebon, Sukoharjo, Surakarta, dan Jakarta - Bogor - Depok - Tangerang - Bekasi (Jabodetabek) [3]. Sentra di Provinsi Jawa Tengah sendiri terdapat di daerah Jepara, Semarang, dan Solo. Pada tahun tersebut, di provinsi Jawa Tengah memiliki 374 perusahaan yang bergerak di bidang furnitur dengan 46.786 tenaga kerja. [4]

Salah satu perusahaan furnitur yang ada di Jawa Tengah adalah UD Surya Abadi Furniture. Perusahaan ini berdiri sejak tahun 2002 dan berlokasi di Desa Trangsan, Kecamatan Gatak, Kabupaten Sukoharjo, Provinsi Jawa Tengah. Produk yang dihasilkan UD Surya Abadi Furniture terdiri dari berbagai jenis dengan bahan utama adalah kayu dan rotan. Meskipun masih tergolong industri sedang dengan 80 orang pekerja, UD Surya Abadi Furniture berfokus pada pasar internasional. Negara yang diekspor antara lain seperti Amerika Serikat, Belgia, Perancis, Belanda, dan Spanyol. 
Kendala yang dihadapai industri furnitur dalam perdagangan furnitur di pasar global setidaknya harus memperhatikan empat pilar utama. Empat pilar yang menentukan daya saing produk ekspor furnitur Indonesia yaitu, bahan baku, proses produksi, desain dan inovasi, serta pemasaran. Terkait dengan bahan baku, faktor yang mempengaruhi adalah standarisasi kualitas bahan baku, stabilitas harga, kepastian pasokan, efisiensi mata rantai distribusi, teknologi pengelolaan, keberlangsungan jangka panjang, dan infrastruktur. [3]

Salah satu aspek yang perlu diperhatikan dalam usaha ekspor seperti yang telah dijelaskan sebelumnya adalah yang terkait dengan mata rantai distribusi. Supply chain atau rantai pasok atau logistik merupakan salah satu faktor penting untuk meningatkan keunggulan perusahaan dalain persaingan global [5]. Supply chain management sebagai koordinasi dari keseluruhan kegiatan rantaí pasokan, dimulai dari bahan baku dan diakhiri dengan pelanggan yang puas [6]. Tujuan daii supply chain management adalah untuk mengøordinasi kegiatan dalam rantai pasokan untuk memaksimalkan keunggulan kompetitif dan manfaat dari supply chain bagi konsumen/akhir, sehingga diperlukan rekonsiliasi antara kebutuhan pelanggan akhir dengan kemampuan sumber daya yang ada pada jaringan rantai pasok [7]. Supply chain management berfokus pada upaya mengintegrasikan dan mengelola aliran barang dan jasa dan informasi melalui supply chain untuk membuatnya responsif terhadap kebutuhan pelanggan sambil menurunkan total biaya.[8]

Pada umumya kesalahan dalam proses pengiriman barang dari manufaktur kepada konsumen (Forward Logistics, FL) tersebut mengakibatkan adanya proses pengiriman kembali produk kepada manufaktur (Reverse Logistics, RL) untuk diperbaiki. Kemudian, produk yang telah diperbaiki akan dikirimkan ulang ke retailer. Dengan kata lain, terjadi dua kali aktivitas distribusi untuk produk yang mengalami cacat akibat distribusi. Selain itu, produk yang cacat akan merugikan secara bisnis karena memunculkan biaya perbaikan (service), memunculkan backlog dan menurunkan tingkat kepuasan konsumen.[7]
Berkaitan dengan hal tersebut, maka proses packaging dan stuffing menjadi hal yang penting. Proses packaging sendiri pada intinya merupakan proses pengemasan/pengepakan/pembungkusan setiap produk untuk menjamiin produk yang dikirimkan aman sampai ke tangan konsumen. Sedangkan stuffing sendiri merupakan aktivitas dalam penataan dan penempatan produk yang sudah di-packing dan dikirin melalui kontainer. Dengan sistem packaging dan stuffing yang baik, produsen dapat meninimalkan kerusakan produk pada saat distribusi, serta dapat mengoptimalkan kontainer sebaik inungkin agar dapat mengangkut produk secara optimal sesuai kapasitas kontainer.

Pengemasan merupakan salah satu keputusan perting dalam pembuatan produk ritel, selain keputusan lain seperti, penentuan atibut produk, branding, labeling, dan layanan purna jual [9]. Pengemasan merupakan kegiatan mewadahi produk, melindungi, menjaga kondisi, memindahkan, dan menginformasikan produk agar produk terjual dan digunakan konsumen. Pengemasan sendiri merupakan gabungan dari ilmu pengetahuan, seni, desain, dan teknologi untuk membungkus, menutupi, atau melindungi suatu produk agar produk tidak rusak selama proses distribusi, penyimpanan, penjualan, hingga penggunaannya oleh konsumen [10]. Melihat persaingan bisnis yang semakin ketat, setiap proses produksi harus mampu menghasilkan nilai tambah (value added) agar mampu bertahan dalam persaingan.[11]

Packaging dapat dikategorikan menjadi beberapa jenis. Pengelompokkan pengemasan dalam konteks logistik tersebut antara lain, pengemasan primer, yaitu bahan yang membungkus dan mewadahi langsung suatu produk; pengemasan sekunder, yaitu untuk menyatukan beberapa pengemasan primer; dan pengemasan tertier, yaitu pengemasan untuk menangani pengemasan sekunder dalam jumlah lebih banyak untuk penyimpanan di gudang ataupun pengangkutan dalam kontainer.[10]

Dalam konteks pengemasan, terdapat enam persyaratan pengemasan yang baik. Pertama, dapat melindungi dan menjaga isi barang. Produk yang disimpan dalam kemasan membutuhkan perlindungan terhadap getaran, benturan, elektrostatis, tekanan, temperatur, dan lain- lain. 
Selain itu, kemasan harus dapat menjaga produk dari paparan oksigen, air, dan debu. Kedua, mewadahi dalam satuan kemasan (unitization). Barang-barang kecil biasanya dikelompokkan dalam satu kemasan untuk efisiensi penanganan. Ketiga, indentifikasi dan informasi yang jelas di setiap tahapan proses logistik. Kemasan dan label juga berisi informasi tentang bagaimana menggunakan, menyimpan, mengangkut, menangani, me-recycle, dan bagaimana membuang produk atau kemasan itu sendiri. Keempat, kemenarikan kemasan dalam pemasaran (market appeal). Pengepakan dan label dapat digunakan oleh tim pemasaran untuk meyakinkan calon pembeli agar membeli produk tersebut. Desain grafis kemasan maupun desain dari kemasan itu sendiri merupakan bagian penting dan inovasi yang terus dilakukan. Komunikasi marketing dan desain grafis dibuat pada permukaan bahan kemasan dan sering pula dibuat pada point of sale display. Kelima, keamanan terhadap keutuhan isi kemasan. Pengepakan memainkan peranan yang penting dalarn mengurangi risiko keamanan dalam pengiriman. Pengepakan dapat dibuat dengan anti-pendodosan untuk mencegah terjadinya pendodosan, dan sebaliknya dapat juga dibuat agar bila terjadi pendodosan akan tampak bekasnya sehingga dapat dengan cepat diketahui. Terakhir, keenam, kemudahan proses penanganan dan perlakuan dalam transport. Pengepakan harus dirancang agar mudah dalam penggunaan atau proses pengepakannya, penanganan secara manual, maupun penanganan dengan mekanisasi atau otomatisasi. Pengepakan harus dirancang agar memberi kemudahan dalam unitisasi, pendistribusian, penumpukan, penyimpanan, tidak membuang ruang, display, penjualan, mudah dibuka, mudah ditutup lagi, mudah digunakan, dibuang, dan digunakan.[10]

Setelah proses packaging, maka proses selanjutnya yang berkaitan dengan distribusi produk adalah stuffing. Stuffing adalah kegiatan penataan barang yang telah selesai dikemas ke dalam kontainer dengan memberikan kode-kode yang sudah ditentukan dalam shiping mark dan dihitung untuk dasar pembuatan packaging list dan invoice. [12]

Inti dari proses stuffing adalah bagaimana mencapai efisiensi dalam salah satu tahap distribusi produk, yaitu pada saat penataan produk di dalam kontainer. Penataan yang baik akan berdampak pada pengoptimalan penggunaan ruang yang tersedia di kontainer, sehingga dapat memuat lebih banyak barang. Selain itu, penataan yang baik juga berdampak pada berkurangnya/resike kerusakan barang pada saat pengiriman.

Berdasarkan hasil observasi, UD Surya Abadi Furniture mengalami beberapa kendala terkait proses packaging dan stuffing. Kendala dalam proses packaging melipui kerusakan produk pada saat akan dikemas, permintaan tertentu dari konsumen terkait bahan paekaging, dan beberapa masalah seperti ukuran karton box yang tidak sesuai dengan produk. Kemudian pada proses stuffing juga mengalami berbagai kendala, seperti kesalahan dalam penumpukkan barang di dalam kontainer, waktu stuffing yang lama sedangkan konsumen menginginkan proses stuffing dapat berjalan cepat, serta kurangnya pengecekan pada kondisi kontainer yang terkadang terdapat kebocoran.

Berbagai kendala tersebut tentu berdampak pada tingkat kepuasan konsumen, terutama pada produk ekspor. Kendala tersebut dapat merugikan bagi konsumen atau produsen dalam contoh kasus ketika barang dikembalikan karena setelah sampai pada konsumen ternyata terdapat produk yang mengalami kerusakan. Dan kerusakan ini karena kurangnya perhatian pada proses packaging dan stuffing yang diberlakukan di UD Surya Abadi Furniture.

Atas dasar latar belakang itulah, peneliti melakukan penelitian untuk melihat bagaimana kondisi sistem packaging dan stuffing yang diterapkan pada UD Surya Abadi Furniture. Hal ini karena melihat UD Surya Abadi Furniture sebagai salah satu representasi industri furnitur lokal, khususnya di Provinsi Jawa Tengah yang hingga kini masih mampu bertahan untuk memproduksi produk furnitur dan mengekspornya ke berbagai negara. Oleh karena itu, penelitian ini merumuskan pertanyaan penelitian: pertama, bagaimanakah sistem packaging yang diterapkan di UD Surya Abadi Furniture? Kedua, bagaimanakah sistem stuffing yang dilakukan di UD Surya Abadi Furniture? 
Melaui penelitian ini, peneliti bertujuan untuk dapat menjelaskan bagaimana proses kegiatan packaging dan stuffing yang dilakukan oleh salah satu industri furnitur yang ada di Jawa Tengah. Sehingga dengan demikian, dapat dipaparkan deskripsi kegiatan packaging dan stuffing di industri furnitur lokal. Hal ini menjadi penting melihat persaingan industri furnitur yang semakin ketat, serta posisi industri furnitur Indonesia yang semakin sedikit proporsinya dalam peta persaingan usaha industri furnitur dunia. Selain itu, hasil penelitian juga dapat dimanfaatkan oleh perusahaan furnitur lokal, khususnya UD Surya Abadi Furniture sebagai bahan telaah dan bahan koreksi dalam mengembangkan proses packaging dan stuffing yang lebih baik.

\section{METODE PENELITIAN}

\section{Ruang Lingkup penelitian}

Penelitian ini dilakukan di salah satu industri furnitur, yaitu UD Surya Abadi Furniture, yang berlokasi di Desa Trangsan, Kecamatan Gatak, Kabupaten Sukoharjo, Provinsi Jawa Tengah. Peneltian ini dilakukan pada rentang waktu: bulan Februari sampai bulan Maret Tanun 2016. Perusahaan ini dipilih karena UD Surya Abadi Furniture merupakan salah satu perusahaan furnitur yang telah berhasil mengekspør produknya ke berbagai negara. Perusahaan ini juga telah berdiri sejak tahun 2002, dan konsisten dalam memproduksi produk furnitur terutana yang berbahan utama rotan dan kayu.

\section{Sumber Data}

Sumber data yang diperoleh dalam penelitian ini berupa data primer dan data sekunder. Data primer berupa deskripsi atas pengamatan yang peneliti lakukan, wawancara, tata cara drop test, dan dokumentasi kegiatan. Data sekunder yang peneliti peroleh digunakan sebagai pendukung dalam penyusunan hasil penelitian ini. Data tersebut merupakan tulisan ilmiah yang berkaitan dengan packaging dan stuffing dalam pengelolaan industri.

\section{Metode Pengumpulan Data}

Metode pengumpulan data yang digunakan peneliti adalah observasi partisipatif, wawancara tidak terstruktur, serta dokumentasi. Peneliti melibatkan diri dalam keseharian pelaku yang diteliti, mengamati apa yang dikerjakan orang, mendengarkan apa-apa yang diucapkan, dan berpartisipasi dalam aktivitas terteliti [14]. Melalui teknik pengumpulan data ini, yang menjadi instrumen utama penelitian adalah peneliti sendiri. Sehingga peneliti dapat mengumpulkan data berupa deskripsi tentang bagaimana berjalannya proses packaging dan stuffing yang dilakukan di UD Surya Abadi Furniture.

\section{Teknik Analisis Data}

Teknik analisis data yang dilakukan dalam penelitian ini dilakukan dalam tiga prosedur. Pertama adalah reduksi data, yang dilakukan dengan merangkum, memilah hal-hal yang pokok, kemudian mencari pola dan temanya. Kedua adalah penyajian data, yaitu mendeskripsikan sekumpulan informasi dengan tujuan untuk memudahkan pemahaman atas apa yang terjadi selama penelitian dijalankan. Terakhir adalah verifikasi data, yaitu penyesuaian data dengan kondisi yang sebenarnya terjadi sehingga dapat membangun kesimpulan yang kredibel dan dapat dipercaya.

\section{HASIL DAN PEMBAHASAN}

\section{Packaging UD Surya Abadi Furniture}

Sebagai bentuk upaya menjaga kualitas produksi, UD Surya Abadi Furniture memberikan perhatian lebih terhadap proses akhir produksi, yaitu packaging. Hal ini berlandasakan komitmen perusahaan untuk memberikan hasil produksi yang berkualitas sampai pada tangan konsumen. Tahap packaging kemudian secara opsional disertai dengan uji packaging untuk mengukur sejauh mana tingkat kemanan produksi yang telah dikemas dan siap kirim.

Uji packaging yang dimaksud adalah dengan pelaksanaan drop test. Drop test secara konseptual berfungsi untuk menguji bagaimana kekuatan packing yang dilakukan dapat melindungi produk yang dikirim. Tidak dapat dipungkiri bahwa dalam proses pengiriman barang, besar kemungkinan paket yang dikirim dapat terjatuh, tertumpuk, dan terlempar sehingga kemungkinan berakibat pada paket yang penyok bahkan rusak. Meskipun 
demikian, drop test dilakukan oleh UD Surya Abadi Furniture secara opsional, artinya berdasarkan permintaan konsumen. Hal ini karena pelaksanaan drop test membutuhkan biaya tambahan, sehingga konsumen yang menginginkan pengujian drop test harus bersedia membayar biaya tambahan.

Proses packaging yang dilakukan UD Surya Abadi Furniture melalui mekanisme yang sudah terlembaga. Proses tersebut ditunjukkan dalam gambar berikut.

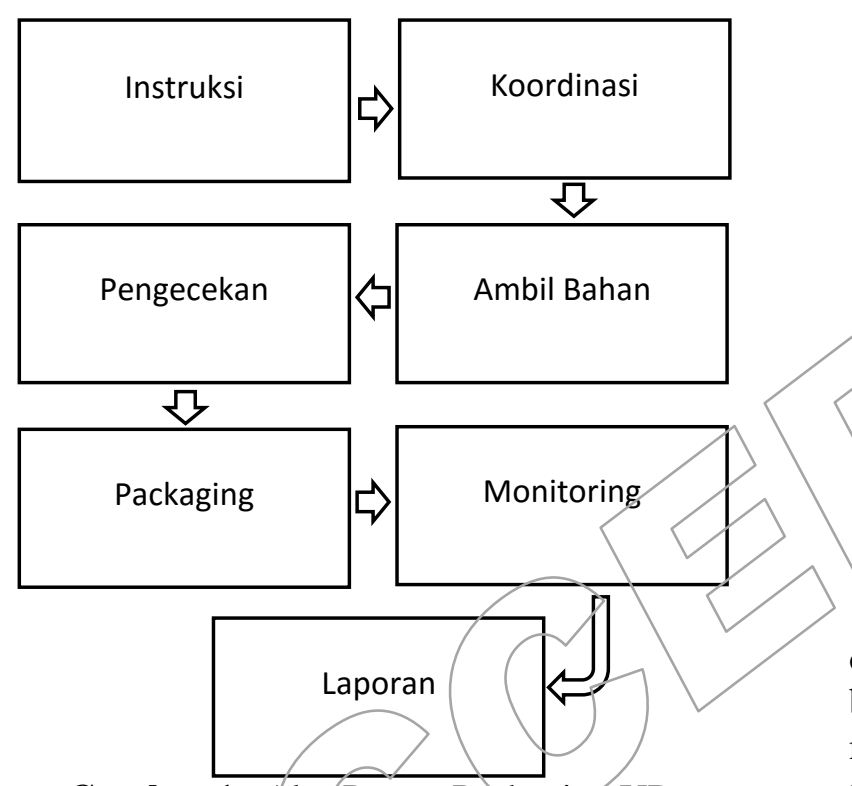

Gambar 1. Alur Proses Packaging UD

Gambar tersebut menjelaskan mengenai mekanisme packaging di UD Surya Abadi Furniture yang dimulai dari proses intruksi dan diakhiri dengan penyusunan laporan. Tahap instruksi maksudnya kepala produksimengintruksikan kepada kepala regu packaging untuk melakukan packaging berdasarkan perencanaan shipment yang diterima. Tahap selanjutnya yaitu koordinasi kepala regu packaging dengan pegawai bagian packaging. Kemudian, pegawai packaging mengambil bahan dan label sesuai instruksi kerja kepada bagian gudang, yang dilanjutkan dengan pengecekan dari kepala regu packaging. Setelah bahan siap, pegawai packaging melakukan proses packaging dengan dibawah monitor kepala regu packaging. Proses terakhir adalah pembuatan laporan yang berisikan hasil kerja packaging.
Bahan packaging yang digunakan oleh UD Surya Abadi Furniture mengikuti standar ISO, hal ini untuk menjaga kualitas barang produksi. Setidaknya ada 5 jenis bahan utama yang digunakan dalam proses packaging, antara lain sebagai berikut.

\section{Single Face}

Single face merupakan jenis bahan pembungkus utama untuk produk furnitur yang tidak beraturan.

2. Carton Box

Carton box digunakan untuk packing dengan bentuk beraturan seperti persegi dan persegi panjang.

3. Polywarp

Polywrap digunakan untsk melindungi stainless dari gesekan/goresan saat packing dan stuffing .

4. Onionskin

Onionskin merupakan bahan packaging yang digunakan untuk melapisi permukaan produk dari gesekan/goresan.

5. Gabus

Gabus berfungsi sebagai peredam benturan pada produk furnitur.

Proses packaging produk furnitur yang dilakukan oleh UD Surya Abadi Furniture dilakukan dalam beberapa tahap. Pertama-tama adalah mempersiapkan alat yang digunakan, seperti tali rafia, cutter, gunting, penjapit, lem, klem, stapping band, serta label produk. Langkah selanjutnya adalah pengecekan pada produk, jika diperlukan maka dilakukan pengamplasan pada bagian produk yang masih kurang rapi. Kemudian melapisi bagian ujung sisi produk dengan onionskin, yang bertujuan agar warna tetap terlindungi ketika terjadi gesekan. Bagian rangka stainless dibalut dengan polywrap serta mengemas aksesori produk dengan plastik. Kemudian memasang bahan packaging dengan single face secara menyeluruh pada tiap bagian untuk melindungi produk dari gesekan saat stuffing. Terakhir, memasang label yang sesuai dengan nama produk pada sisi carton box sebagai identitas produk.

\section{Drop Test}

Mekanisme drop test merupakan uji untuk mengetahui tingkat keamanan barang yang telah dipacking. Melalui uji ini, diharapkan dapat meminimalkan terjadinya kerusakan pada saat 
pengiriman. Seperti yang telah dijelaskan sebelumnya, pelaksanaan drop test merupakan permintaan dari pembeli, dan bukan disediakan secara otomatis oleh produsen. Hal ini karena uji dengan drop test diperlukan biaya tambahan dengan kualitas bahan packaging yang lebih baik serta memerlukan waktu yang lebih lama dibandingkan dengan waktu yang diperlukan packaging biasa.

Packaging dengan drop test membutuhkan bahan yang lebih berkualitas. UD Surya Abadi Furniture menambahkan tambahan bahan pelindung (foam) dan carton box yang lebih tebal dengan penggunaan double wol. Penggunaan tambahan barang ini dapat meningkatkan keaman produk furnitur yang akan dikirim.

Pelaksanaan packaging dengan drop test dan tidak dengan drop test sebenarnya sama saja, terkecuali dengan penggunaan material tambahan packaging seperti yang telah dijelaskan sebelumnya. Setelah produk selesai packaging, tahap drop test dapat dimulai. UD Surya Abadi Furniture melakukan drop test secara manual dengan pengujian menjatuhkan barang pada titik dan sudut tertentu serta pada ketinggian tertentu sesuai aturan yang ada. Pelaksaan drop test ini diawasi langsung oleh kepala bagian produksi. Setelah proses uji menjatuhkan barang selesai, kemudian dilakukan unpackaging untuk mengecek kondisi barang serta menganalisis tingkat keamanan serta kerusakan yang mungkin dapat terjadi. Pelakasanaan drop test ini juga didokumentasikan guna dikirim kepada pembeli sebagai laporan atas pelaksanaan drop test.

\section{Stuffing UD Surya Abadi Furniture}

Setelah packaging serta drop test selesai dijalankan, maka selanjutnya yang perlu dilakukan adalah pelaksanaan stuffing. Stuffing pada intinya merupakan upaya untuk menata barang yang akan dikirim secara optimal sehingga dapat memaksimalkan ruang terbatas pada kontainer.

Proses stuffing ini mempunyai peran penting dalam rangkaian pengiriman produksi UD Surya Abadi Furniture. Melalui penataan yang baik dengan mempertimbangkan pola penyusunan yang rapi, pembagian berat yang rata, dan packaging yang berkualitas, dapat memberikan perlindungan lebih baik pada resiko kerusakan barang pada waktu pengiriman. Selain itu, stuffing yang baik juga dapat mengurangi biaya transportasi. Hal tersebut dapat meningkatkan citra baik produsen di mata konsumen, serta secara tidak langsung dapat menngkatkan keuntungan perusahaan.

Proses stuffing pada UD. Surya abadi Furniture dilakukan dalam tahap-tahap sebagai berikut:

1. Pembuatan ceklist sesuai dengan packing list.

2. Pemeriksaan kontainer seperti light test, kebersihan, bebas bau, kering, bebas hama, kondisi pintu apakah dapat ditutup dengan baik, dan kondisi atap apakah tidak berkarat atau berlubang.

3. Penataan barang sesuai dengan pola penyusunan, meratakan berat dan menyusun dengan rapi dan teratur.

4. Pemaksimalan dan pengoptimalisasian kapasitas kontainer serta pengikatan barang dengan tali agar tidak goyah pada saat perjalanan.

5. Stuffing selesai, kemudian dilakukan proses fumigasi.

6. Terakhir adalah pemasangan sealing dan gembok pada kontainer.

Mekanisme dalam stuffing pada intinya mengoptimalkan penggunaan ruang kontainer untuk diisi dengan barang produksi yang akan dikirim. UD Surya Abadi Furniture menggunakan metode stuffing dengan mengecek perbandingan antara volume kontainer dengan volume barang. Penghitungan ini dapat digunakan sebagai acuan dalam melihat seberapa banyak barang yang dapat masuk ke kontainer. Selain itu, juga dilihat bagaimana menentukan pengaturan posisi barang di dalam kontainer. Hal ini dilakukan dengan melihat ukuran kontainer dengan carton box.

\begin{tabular}{|l|l|l|l|l|l|}
\hline No & Jenis & Ukuran & $\begin{array}{l}\text { Ukuran } \\
\text { dalam } \\
\text { kontainer } \\
40 ”\end{array}$ & $\begin{array}{l}\text { Ukuran } \\
\text { Luar } \\
\text { Carton } \\
\text { Box }\end{array}$ & $\begin{array}{l}\text { Perban- } \\
\text { dingan }\end{array}$ \\
\hline 1 & Ukuran & Panjang & $\begin{array}{l}12032 \\
\mathrm{~mm}\end{array}$ & $\begin{array}{l}1430 \\
\mathrm{~mm}\end{array}$ & 8,41 \\
\hline & & Lebar & $2352 \mathrm{~mm}$ & $\begin{array}{l}440 \\
\mathrm{~mm}\end{array}$ & 5,34 \\
\hline & & Tinggi & $2698 \mathrm{~mm}$ & $\begin{array}{l}560 \\
\mathrm{~mm}\end{array}$ & 4,81 \\
\hline
\end{tabular}




\begin{tabular}{|l|l|l|l|l|l|}
\hline 2 & $\begin{array}{l}\text { Kapa- } \\
\text { sitas }\end{array}$ & $\mathrm{m}^{3}$ & $76 \mathrm{~m}^{3}$ & $\begin{array}{l}0,34 \\
\mathrm{~m}^{3}\end{array}$ & 223,52 \\
\hline
\end{tabular}

Tabel 1. Perbandingan Ukuran dalam Container Dengan Ukuran Karton Box

Penghitungan pada tabel di atas menjadi acuan UD Surya Abadi Furniture dalam melakukan mekanisme stuffing. Meskipun masih dilakukan secara manual, UD Surya Abadi Furniture menganggap hal ini masih dapat digunakan walaupun dengan tingkat akurasi yang kurang tinggi.

Waktu yang dibutuhkan dalam proses stuffing UD Surya Abadi Furniture bervariasi tergantung pada kapasitas kontainer dan jumlah barang. Pada kontainer dengan ukuran 20' dibutuhkan waktu kurang lebih 2 jam. Pada ukuran kontainer 40 standar dibutuhkan waktu kurang lebih 3 jan. Kemudian pada ukuran kontainer 40` highcube dibutuhkan waktu kurang lebih 4 jam.

Menurut UD. Surya Abadi Furniture, staffing yang dilakukan dengan efektif dapat menberikan berbagai keuntungan. Pertama, perlindưngan lebih baik pada kerusakan barang. Penataan yang tepat yaitu dengan pembagian berat yang merata, pola penyusunan yang rapi, dan didukung packaging yang berkualitas, maka dimungkinkan dapat menekan angka kerusakan produk seminimal mungkin dalam proses distribusi. Kedua, mengurangi biaya transport. Penataan barang yang maksimal dengan cara memanfaatkan setiap ruang kosong di kontainer, hal tersebut mengindikasikan barang yang dimuat semakin banyak, sehingga berpengaruh pada biaya trucking yang menjadi lebih rendah. Ketiga, meningkatkan keuntungan perusahaan. Hal ini terkait dengan dua keuntungan sebelumnya, dimana perusahaan dapat meminimalkan biaya serta menjamin kualitas barang tetap terjaga sampai pada tangan konsumen, sehingga secara tidak langsung juga dapat meningkatkan citra baik perusahaan terhadap konsumen.

\section{KESIMPULAN}

Berdasarkan hasil penelitian yang telah dilakukan, UD. Surya Abadi Furniture menjalankan mekanisme packaging dan stuffing secara baik dan tersistem. Sudah terdapat divisi tersendiri yang bertanggungjawab pada bagian packaging dan stuffing menunjukkan perhatian perusahaan pada proses ini. Bahan yang digunakan untuk proses packaging juga sudah memenuhi standar untuk pengemasan produk furnitur, sehingga dapat meminimalkan tingkat kerusakan produk furnitur dalam proses pengiriman. Oleh karena itu, perusahaan ini tetap dapat bertahan dalam persaingan pasar furnitur dunia.

Waktu dan sumberdaya dalam proses packaging dan stuffing di UD Surya Abadi/Furniture masih terdapat celah untuk dioptimalkan. Pengembangan teknologi, pengadaan pelatihan bagi pekerja serta menjaga produktivitas pekerja yang tinggi dapat meningkatkan mutu [13]. Pelaksanaan metode drop test, meskipun hanya dilakukan ketika ada permintaan dari konsumen, tetapi pelaksanaannya masih dilakukan secara manual. Oleh sebab itu disarankan agar UD. Surya Abadi Furniture dapat menggunakan alat drop tester sehingga lebih terpercaya di mata konsumen dan mendapatkan hasil yang lebih optimal. Selain itu, proses stuffing juga masih menggunakan penghitungan secara manual untuk menyiapkan rancangan penataan barang pada kontainer. Hal ini dapat dimaksimalkan, baik mengurangi waktu dan tenaga dengan cara menggunakan software pengaturan stuffing, sehingga proses stuffing dapat dilakukan secara optimal dengan memanfaatkan seluruh ruang di kontainer secara maksimal.

\section{DAFTAR PUSTAKA}

[1] E. Mundai, "Furnitur, Produk Berdaya Saing Yang Butuh Perhatian," in Info Komoditi Furnitur, Z. Salim and E. Munadi, Eds. Jakarta: Badan Pengkajian dan Pengembangan Perdagangan, Kementerian Perdagangan Republik Indonesia, 2017.

[2] Bank Indonesia, "Pola Pembiayaan Usaha Kecil (PPUK) Furnitur Kayu," Jakarta, 2008.

[3] Asosiasi Mebel dan Kerajinan Indonesia, "Roadmap Industri Mebel dan Kerajinan Indonesia 'Target Pencapaian Ekspor 5 Milyar USD,"” Jakarta, 2015.

[4] Himpunan Industri Mebel dan Kerajinan Indonesia, "10 Langkah Meningkatkan Daya 
Saing Industri Mebel dan Kerajinan di Pasar Global." Himpunan Industri Mebel dan Kerajinan Indonesia (HIMKI), Jakarta, 2016.

[5] Supply Chain Council, "Supply Chain Operations Reference Model Overview," Supply Chain Council, 2010. [Online]. Available: supply-chain.org. [Accessed: 07May-2016].

[6] J. Heizer and R. Barry, Operations Management: Sustainability and Supply Chain Management, 11th ed. Jakarta: Salemba Empat, 2014.

[7] P. K. Ariningsih, I. . Sandy, and I. C. D. Adventia, "Pengembangan Sistem Operasional Downstream Logistics dengan Modifikasi P1R2," J. Metris, vol. 17, pp. 71-80, 2016.

[8] R. R. S. and T. B. W, Operation Management. United States of America: Wiley, 2006.

[9] P. Kotler and G. Amstrong, Principles of Marketing, 13th ed. United States of America: Pearson, 2010.
[10] Zaironi, "Packaging," Supply Chain Indonesia, 2017. [Online]. Available: http://supplychainindonesia.com/new/packag ing/. [Accessed: 03-Jun-2016].

[11] S. P. Puar and M. T. Siregar, "Rancangan Sistem Elektronik Kanban untuk Meningkatkan Efektivitas Produksi Just In Time," J. Manaj. Ind. dan Logistik, vol. 1, no. 1, pp. 86-93, 2017.

[12] R. P. Suyono, Shipping Pengangkutan Intermodal Ekspor Impor Melalui Laut, 3rd ed. Jakarta: PPM, 2003.

[13] A. Darmawi, Darsono, D. T. Kartono, and S. Anantanyu, "Pengaruh Variabel Peningkatan Produktivitas, Penguasaan Teknologi Baru dan Pelatihan Terhadap Pengendalian Mutu Terpadu Karyawan Pada Industri Tekstil dan Garmen di Surakarta," J. Manaj. Ind. dan Logistik, vol. 2, no. 1, pp. 3-13, 2018.

[14] Y. P. Pratama. Penelitian Kualitatif: Modul Metode Pengumpulan Data. Riau: CV. Draft

Media

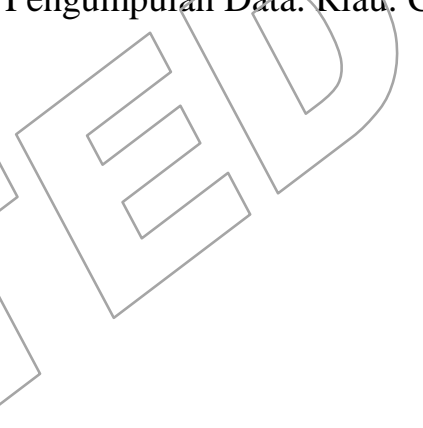

